\title{
Externalising Behaviour in Children: An Integrative Model Between Health and Education
}

\section{Santuri Rungan ( $\sim$ Santuri.Rungan@health.nsw.gov.au )}

Croydon Community Health Centre

\author{
Alicia Montgomery \\ Croydon Community Health Centre \\ Jennifer Smith-Merry \\ The University of Sydney \\ Huei Ming Liu \\ Croydon Community Health Centre \\ John Eastwood \\ Croydon Community Health Centre
}

\section{Research Article}

Keywords: Externalising behaviour, Conduct Disorder, Oppositional Defiant Disorder, school and health, multidisciplinary

Posted Date: July 20th, 2021

DOI: https://doi.org/10.21203/rs.3.rs-723269/v1

License: (c) (i) This work is licensed under a Creative Commons Attribution 4.0 International License. Read Full License 


\section{Abstract}

Background: Externalising behaviours are the most common mental health disorder of childhood and adolescence. They are defined as attention deficit and hyperactivity disorder (ADHD) and conduct disorder (CD). CD is associated with high societal and economic burden.

Yudi Gunyi School caters for students aged 10-16 years with problematic externalising behaviour. A multidisciplinary health assessment has been developed.

This evaluation aimed to see if this model of care improved the outcomes for children with externalising behaviour.

Methods: A retrospective evaluation of all students attending the health assessment between 26 July 2016 and 14 May 2019 using de-identified data was conducted.

Descriptive statistics (proportion, mean, SD, and range) were used. A student's t-test was used to assess change in SDQ scores.

Results: Prior to the assessment $22.8 \%$ had a paediatrician but 33.3\% were not engaged with the paediatrician. Similarly, mental health services were involved in $27.8 \%$ but $18.2 \%$ were not engaged. Child protection services had previous involvement with $43 \%$ and current involvement with $32.9 \%$.

Attendance was high (failure to attend 7.6\%; cancellation 8.9\%). New diagnoses of ADHD (3.8\%), autism (1.3\%), CD (1.3\%) and ODD (1.3\%) were made. Other issues identified included learning difficulties (12.7\%), medical diagnoses (10.1\%), emotional concerns (16.5\%), domestic violence (12.7\%), OOHC (7.6\%), trauma background (27.8\%), the death/loss of a close relative/friend (8.9\%), parental separation (31.6\%) and substance use (19\%).

SDQ teacher reports showed a statistically significant decrease in total difficulties scores $(M=6.2, S D=6.165, p<$ 0.05 , eta squared $=1.013$ (large effect) $)$ and all subsets including behavioural/conduct difficulties $(M=1.8, S D=2.4, p$ $<0.05$, eta squared $=0.741$ (medium effect)), hyperactivity and concentration difficulties $(M=2.8, S D=2.4, p<0.05$, eta squared 1.15 (large effect)) and impact scores $(M=1.636, S D=1.8, P<0.05$, eta squared $=0.909$ (large effect)).

There were no significant differences in the parent and self-reported SDQs.

Conclusions: The multidisciplinary model between health and education offered mechanisms to reduce barriers to care for children experiencing externalising behaviours.

\section{Introduction}

In 1948, the World Health Organization defined health as a "state of complete physical, mental and social well-being and not merely the absence of disease or infirmity" (1). In 1959 the United Nations Convention on the Rights of Children described the responsibilities of governments to ensure that every child had the right to the best health care possible and the right to an education(2).

The health and wellbeing of children is scaffolded by the concepts of family, community, and education. For children and young people the institutions that play the most significant roles in achieving wellbeing are schools and health systems(3). As such, it is important for these two sectors to work collaboratively. When done effectively, this can have a significant impact on learning and health outcomes while reducing barriers to access $(4,5)$. Children who are in good health have a better chance of reaching their developmental potential (3). 
Globally, externalising behaviours are the most common mental health disorder of childhood and adolescence. Patterns of externalising behaviour are defined as attention deficit and hyperactivity disorder (ADHD) and conduct disorder (CD) (6-8). CD is associated with high societal and economic burden. It accounts for about $1 \%$ of all years

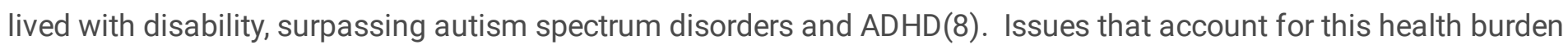
include educational problems such as early school dropout, social issues like poor marital adjustment, occupational challenges including poor job performance, and physical health problems such as poor respiratory function $(9,10)$.

$\mathrm{CD}$ is estimated to have a $5 \%$ global prevalence and is twice as prevalent in males than in females $(8,11)$. The term CD is generally used to encompass oppositional defiant disorder (ODD) and CD. Both refer to antisocial behaviour with ODD used to describe younger children and $C D$ to describe older children $(8,11)$. CD can further be subtyped according to age at onset (childhood- onset versus adolescent- onset) and the presence or absence of callous- unemotional traits(8). CD frequently co- occurs with ADHD and can be a precursor to antisocial personality disorder in adulthood(8).

The aetiology of $C D$ is complex with genetic and environmental factors playing a role. In the antenatal period risk factors include exposure to cigarette smoking, alcohol, drugs and maternal stress. At birth, complications arising from birthing, parental psychopathology and malnutrition are risk factors. During childhood and adolescence other risk factors include harsh and inconsistent disciplining, parent-child conflict, maltreatment, low socio-economic status, community violence and association with socially deviant peers(8). Genetic heritability is estimated to be around 40$50 \%$ and is higher in males than females $(12,13)$. The genetic contribution to CD increases from childhood to adolescence but is not stable over time, suggesting an interplay between different genes at different points of development $(14,15)$.

A significant and detrimental outcome of $C D$ is incarceration. A systematic review of 47 studies from 19 countries comprising 28,033 male and 4,754 female adolescents showed that $61.7 \%$ of male adolescents in custody had a diagnosis of CD compared with $59.0 \%$ of female adolescents(16). Locally, studies from Tasmania and Sydney showed that $91-98 \%$ of those in in youth detention centres presented with CD along with other psychological disorders $(17,18)$.

Indigenous youth are over-represented in detention centres by a factor of about 20 times(19). A study of 242 incarcerated youth in New South Wales, Australia showed that Indigenous youth were significantly more likely to have a diagnosis of $C D(72.21 ; S D=13.80)$ than non-Indigenous youth $(65.52 ; S D=14.23)(19)$. The potential reasons for this over-representation include a legal system that is systemically biased against Indigenous people, that Indigenous people have higher levels of social disadvantage, and that Indigenous people have higher rates of alcohol and illicit substance use which is associated with juvenile offending(19). This necessitates viewing CD through a cultural lens by working in partnership with the local Indigenous community(20).

Yudi Gunyi School (YGS) is a School for Special Purposes (SSP) located in central Sydney, Australia. It caters for students from 10-16 years of age who need additional support with problematic externalising behaviour and mental health needs. An individual case management approach is used to equip students and their referring school with skills that allow successful transition back into a mainstream school setting, or for students to develop skills that will enhance their ability to access the school curriculum and to positively engage in the wider community(21). The school, in collaboration with the health sector has developed a new model of care, creating a set of universal teaching skills, collegial support channels and clinical services to improve outcomes for children and their families(21).

The clinical component of the model of care is built around a multidisciplinary team including a paediatrician, youth health nurse, school counselling team, occupational therapist, speech pathologist, social worker, art therapist, and 
specialist teachers. The team work collaboratively through a purpose-built area in the school named 'Ngaramadhi Space' (NS). 'Ngaramadhi' means 'active listening' in Dharawal language, the name gifted to the school as a result of ongoing collaboration with the Indigenous community(21).

The goals of the initiative were to address the physical health and psychosocial issues experienced by students and their families. The aim of this evaluation was to see if the joint collaborative model of care developed between health and education improved the outcomes for children with externalising behaviour.

\section{Methods}

\section{Study Design AND SETTING}

A retrospective evaluation of all students attending NS between 26 July 2016 and 14 May 2019 was conducted using de-identified electronic medical record (EMR) data. NS was a physical space located within YGS, which was located in inner city Sydney. When students were enrolled at YGS they were offered a comprehensive health assessment at NS. Participation in this assessment was voluntary.

Sociodemographic data from the EMR was extracted and included age, gender, race, ethnicity, primary language spoken, and whether an interpreter was required. Other data collected using EMR included engagement with a paediatrician or mental health service, previous or current open case with child protection services (Department of Communities and Justice (DCJ)) and prior diagnoses.

The Strengths and Difficulties Questionnaire (SDQ) was used to measure social-emotional wellbeing (SEWB) (22). During the study period, results of the SDQ were collected and entered into the electronic database 'Research Electronic Data Capture (REDCap)' tool hosted at SLHD by NS team members(23). Critical REDCap security components involve user authentication and role-based security. More specifically, the 'User Rights' tool ensured that all survey data entered was confidential and secured, whereby project administrators could restrict access to certain data from research personnel. Survey forms were only accessible to users that had been granted survey access privileges(23).

Full ethics applications were received from the Sydney Local Health District Human Research Ethics Committee (SLHD HREC), NSW State Education Research Applications Process (SERAP) and Aboriginal Health and Medical Research Council (AH\&MRC).

\section{MEASURES AND VARIABLES}

Outcome measures included indicators of physical health and the use of the SDQ to measure SEWB. Physical health was measured by recording clinical activities such as history-taking, physical examination and screening for dental health, vision and hearing. Information and comparisons were made about the reasons for referral, prior diagnoses, new diagnoses made at NS and recommendations that followed.

The SDQ consists of 25 questions. A computerised algorithm was used to predict the risk of a disorder in the following five subscales: conduct problems, emotional problems, hyperactivity/inattention problems, peer relationships and kind and helpful behaviour. An overall score and risk prediction was made for total difficulties and the impact of the behaviours (22). The SDQ was completed by parents, teachers, and children aged 11 years and older. The SDQ was collected at the initial visit and when the child or adolescent returned to their home school on a full time basis. 
The psychometric properties of the SDQ have been examined in various studies. Factor analysis shows that the five subscales correspond with the hypothesised domains of psychopathology and personal strengths $(22,24)$.

The internal consistency and test-retest stability of the SDQ is satisfactory(22). Correlations among parent, teacher, and self-report SDQ scores are moderate and comparable with other psychopathology measures(22, 24-26). The above mentioned psychometric properties are highly similar for the parent and self-report version of the SDQ. Finally, the parent-youth agreement for SDQ scores was reasonable(24).

In terms of validity, SDQ scores correlate well with other indexes of psychopathology such as the Rutter and Achenbach questionnaires (26). The SDQ discriminates well between children with and without psychopathological symptoms $(22,24,25)$ and is effective in screening for child psychiatric disorders in community samples(27).

Amongst Indigenous Australians, the SDQ, with modifications in the wording and the response scale, had high reliability and consistency(20). The Western Australian Aboriginal Child Health Survey (WAACHS) described the wellbeing of 5289 Aboriginal children, 1480 who were aged $12-17$ years $(20,28)$. Four of the five subscales provided good reliabilities (reliability coefficients $=0.77-0.81$ ) with the peer problems scale proving the least reliable $(0.60)$. The overall scale reliability was exceptional (0.93). The internal reliability of the five subscales declined slightly as level of relative isolation increased (20). The SDQ has been used in multiple other settings with Aboriginal children and adolescents including a web based study of 1144 Aboriginal secondary school students(29). The Growing up in Australia: the Longitudinal Study of Australian Children (LSAC) also used the SDQ to measure socio-emotional wellbeing in Aboriginal children(30).

Williamson et al assessed the acceptability and face validity of the SDQ in Aboriginal community controlled health services (ACCHOs) located in the greater Sydney region using a semi-structured approach with 47 participants. The SDQ was found to cover many important aspects of Aboriginal child and adolescent mental health, however, the wording of some questions was considered ambiguous and some critical issues were not explored. The peer relationships subscale did not appear to fit well with Aboriginal concepts of the relative importance of different interpersonal relationships(31).

\section{Data Analysis}

Data was exported from Redcap into SPSS Software in a de-identified format for analysis. Analyses were focused on descriptive statistics (proportion, mean, SD, and range). Change in SDQ scores over time were assessed for statistical significance using a student's t-test after tests of normality were conducted. Significance was defined as $p<0.05$.

\section{Results}

\section{Demographics (Table 1)}

The mean age of students was 12.7 years (range 2.8 -16.2). The younger range of students represent siblings who were seen at the clinic as a preventative approach, given that siblings were at a similar risk of developmental and behavioural issues. Males represented $63.3 \%$ of the sample and females $35.4 \%$. The majority of students identified as being of Australian Caucasian descent (48.1\%). Indigenous Australians formed $35.4 \%$ of the population, compared with $2.8 \%$ in the Australian population(32). English was the predominantly spoken language and no interpreters were required.

Table 1: Demographic information 


\begin{tabular}{|lll|}
\hline & Number & Percentage \\
\hline Age & & \\
\hline Mean & 12.7 \\
\hline Range & 13.4 \\
\hline Minimum & 2.8 & \\
Maximum & 16.2 & \\
\hline Gender & & \\
\hline Female & 28 & 35.4 \\
\hline Male & 50 & 63.3 \\
\hline Cultural Background & & \\
\hline African & 1 & 1.3 \\
\hline Australian Caucasian & 38 & 48.1 \\
\hline Indigenous Australian & 28 & 35.4 \\
\hline Korean & 1 & 1.3 \\
\hline Lebanese & 2 & 2.5 \\
\hline New Zealand Maori & 2 & 2.5 \\
\hline not recorded & 7 & 8.9 \\
\hline Preferred Language & & \\
\hline English & $78.70 \%$ \\
\hline
\end{tabular}

\section{Involvement of Other Services}

Prior to the assessment other services were involved with the students and their families. In this cohort, $22.8 \%$ of students had a paediatrician but about a third (33.3\%) were not engaged with the paediatrician. Mental health services were involved in $27.8 \%$ of cases but about $18.2 \%$ were not engaged with this service. DCJ were involved with $43 \%$ of students in the past and $32.9 \%$ of students had a current open case with DCJ. This acts as marker of increased safety risk and highlights the vulnerability of students seen at the school.

\section{Attendance}

Attendance at the clinic was high with a $7.6 \%$ failure to attend (FTA) rate and $8.9 \%$ cancellation rate. The reasons for FTA were varied. For cancellations in about a third (28.6\%) of cases there were behavioural issues with the child which prevented the family from attending. Other reasons for cancellations included the parent being unable to attend (28.6\%) or clinic variables (28.6\%). This showed a promising high level of initial engagement.

\section{Clinical Activity}


Most of the students were assessed by a paediatrician (97.5\%), a youth health nurse (67.1\%), a school counsellor $(60.8 \%)$ and a social worker (49.4\%). There was a period of between 12 to 18 months were a social worker was not available, which may account for why this figure was lower than the others. The majority of students received a medical history review (97.5\%), physical examination (88.6\%), hearing screening (59.5\%), vision screening (63.3\%) and dental screening (63.3\%).

\section{Diagnostic Information (Table 2)}

The referrals were made by the school and primarily reflect issues pertinent to a child's engagement with the education process. The main reasons for referral were behavioural concerns $(84.8 \%)$. Other reasons included learning difficulties (24.2\%), absenteeism (12.7\%), emotional wellbeing concerns (12.7\%) and social concerns (12.7\%).

Diagnoses recorded prior to the assessment included behavioural concerns (63.3\%) and absenteeism (24.1\%). A DSM 5 diagnosis was present for many. These included ADHD (39.2\%), ASD (3.8\%), CD (12.7\%) and ODD (21.5\%). About $20.3 \%$ were each recorded for learning difficulties, a medical diagnosis, and a mental health diagnosis. Importantly, $6.3 \%$ had concerns around deliberate self harm (DSH)/suicidality. Social vulnerability was previously ascertained with a trauma background identified in $27.8 \%$ and domestic violence in $26.6 \%$. Around $12.7 \%$ had been in out-of-home care (OOHC).

At the assessment the following was added to the above known diagnoses. ADHD was diagnosed in $3.8 \%$, ASD in $1.3 \%, C D$ in $1.3 \%$ and ODD in $1.3 \%$. More notable increases in diagnoses included learning difficulties (12.7\%), medical diagnoses (10.1\%), emotional concerns (16.5\%), domestic violence (12.7\%), OOHC (7.6\%) and a trauma background (27.8\%). There were no formal mental health diagnoses made, primarily because this was outside the scope of practice of the assessors. Where concerns existed a referral to mental health services were made (3.8\%). A further $3.6 \%$ students were identified as experiencing DSH/suicidality.

Importantly, the clinical assessment added a more holistic understanding of the social factors and trauma background of children. These included the death or loss of a close relative or friend, which was identified in $8.9 \%$ (previously identified in 1.3\%), parental separation 31.6\% (from 5.1\%) and substance use 19\% (from 7.6\%). New medical diagnoses were also made. These included obesity $13.9 \%$ (previously $5.1 \%$ ), sexual health concerns $2.5 \%$ (previously $0 \%$ ) and sleep difficulties $8.9 \%$ (previously 3.8\%). This reflects the high needs of this group, who otherwise have limited access to health services.

Table 2: Summary of referral reasons, previous diagnoses and new diagnoses 


\begin{tabular}{|c|c|c|c|c|c|c|}
\hline & \multicolumn{2}{|c|}{ Referral Reason } & \multicolumn{2}{|c|}{ Previous Diagnosis } & \multicolumn{2}{|c|}{ New Diagnosis } \\
\hline & $\mathrm{N}$ & $\%$ & $\mathrm{~N}$ & $\%$ & $\mathrm{~N}$ & $\%$ \\
\hline Absenteeism & 10 & 12.7 & 19 & 24.1 & 1 & 1.3 \\
\hline ADHD & 13 & 16.5 & 31 & 39.2 & 3 & 3.8 \\
\hline ASD & 1 & 1.3 & 3 & 3.8 & 1 & 1.3 \\
\hline Behavioural concerns & 67 & 84.8 & 50 & 63.3 & 3 & 3.8 \\
\hline Conduct Disorder & 2 & 2.5 & 10 & 12.7 & 1 & 1.3 \\
\hline Death or Loss of Close Relative or Friend & 0 & 0 & 1 & 1.3 & 7 & 8.9 \\
\hline Deliberate Self Harm/Suicidality & 0 & 0 & 5 & 6.3 & 3 & 3.8 \\
\hline Dental concerns & 0 & 0 & 4 & 5.1 & 6 & 7.6 \\
\hline Domestic Violence & 0 & 0 & 18 & 22.8 & 10 & 12.7 \\
\hline Emotional concerns & 10 & 12.7 & 21 & 26.6 & 13 & 16.5 \\
\hline Hearing concerns & 0 & 0 & 1 & 1.3 & 0 & 0 \\
\hline Injury & 0 & 0 & 3 & 3.8 & 2 & 2.5 \\
\hline Learning difficulties & 19 & 24.1 & 16 & 20.3 & 10 & 12.7 \\
\hline Medical Diagnosis & 2 & 2.5 & 16 & 20.3 & 8 & 10.1 \\
\hline Mental Health Diagnosis & 6 & 7.6 & 16 & 20.3 & 0 & 0 \\
\hline Obesity & 0 & 0 & 4 & 5.1 & 11 & 13.9 \\
\hline Oppositional Defiant Disorder & 5 & 6.3 & 17 & 21.5 & 1 & 1.3 \\
\hline Out-of-home Care & 0 & 0 & 10 & 12.7 & 6 & 7.6 \\
\hline Parental Separation & 0 & 0 & 4 & 5.1 & 25 & 31.6 \\
\hline School Refusal & 3 & 3.8 & 0 & 0 & 0 & 0 \\
\hline Sexual Health Concerns & 0 & 0 & 0 & 0 & 2 & 2.5 \\
\hline Sleep Difficulties & 0 & 0 & 3 & 3.8 & 7 & 8.9 \\
\hline Social Concerns & 10 & 12.7 & 10 & 12.7 & 11 & 13.9 \\
\hline Substance Use & 3 & 3.8 & 6 & 7.6 & 15 & 19 \\
\hline Trauma Background & 0 & 0 & 22 & 27.8 & 17 & 21.5 \\
\hline Vision Concerns & 0 & 0 & 6 & 7.6 & 4 & 5.1 \\
\hline
\end{tabular}

\section{Recommendations (Table 3)}

In terms of health, the following were most commonly recommended: dental review (36.7\%), drug and alcohol services (16.5\%), medication (13\%), NDIS referral (5.1\%), nutrition support (17.7\%), ongoing review by a paediatrician (20.5\%) 
and referral to a youth health service (43\%). In terms of mental health the following were recommended: counselling (82.3\%), art/music/play therapy (44.3\%). These forms of therapy were often accessed via the school either through the skills of the school counsellor or teachers/therapists. Other therapy uniquely available through NS included trauma-informed occupational therapy (73.4\%) and trauma-informed speech therapy (69.6\%). Education also resourced other recommendations including extracurricular activities (49.4\%), learning support (6.5\%), and a strengthsbased approach to learning (36.7\%).

On the social wellbeing side, a high proportion were referred to a case management service (24.1\%), while others were referred to domestic violence services (11.4\%), DCJ (3.8\%), or a parenting course (20.3\%). Provision of housing support was made in $21.5 \%$.

Table 3: Recommendations 


\begin{tabular}{|c|c|c|}
\hline Recommendations & Number & Percentage \\
\hline Audiology & 9 & 11.4 \\
\hline Art/Music/Play Therapy & 35 & 44.3 \\
\hline Case Management Agency & 19 & 24.1 \\
\hline Cognitive/Developmental/Behavioural Assessment & 34 & 43.0 \\
\hline Continue with Current Mental Health Service & 10 & 12.7 \\
\hline Counselling & 65 & 82.3 \\
\hline Dental Services & 29 & 36.7 \\
\hline Department of Communities and Justice & 3 & 3.8 \\
\hline Domestic Violence Services & 9 & 11.4 \\
\hline Drug and Alcohol Services & 13 & 16.5 \\
\hline Extracurricular Activities & 39 & 49.4 \\
\hline Housing Support & 17 & 21.5 \\
\hline Immunisations & 2 & 2.5 \\
\hline Investigations & 4 & 5.1 \\
\hline Learning Support & 52 & 65.8 \\
\hline Medication & 9 & 13.0 \\
\hline National Disability Insurance Scheme & 4 & 5.1 \\
\hline Nutrition Support & 14 & 17.7 \\
\hline Occupational Therapy & 58 & 73.4 \\
\hline Optometrist & 14 & 17.7 \\
\hline Paediatrician Review & 22 & 27.8 \\
\hline Parenting Course & 16 & 20.3 \\
\hline Referral to a Mental Health Service & 3 & 3.8 \\
\hline Referral to a Medical Service & 6 & 7.6 \\
\hline School/Work Transition Programme & 19 & 24.1 \\
\hline Sexual Health Management & 7 & 8.9 \\
\hline Sibling Review & 4 & 5.063291139 \\
\hline Smoking Cessation advice/programme & 4 & 5.1 \\
\hline Speech Therapy & 55 & 69.6 \\
\hline Stable Environment & 16 & 20.3 \\
\hline Strengths -Based Approach to Learning & 29 & 36.7 \\
\hline Youth Health Service & 36 & 43 \\
\hline
\end{tabular}

Page 10/16 


\section{Strengths and Difficulties Questionnaire (SDQ) (Table 4)}

SDQ teacher reports before and after attending NS $(n=33)$ showed a statistically significant decrease in total difficulties scores $(M=6.2, S D=6.165, p<0.05$, eta squared $=1.013$ (large effect) $)$. This was seen in all the subsets of the SDQ including behavioural/conduct difficulties $(M=1.8, S D=2.4, p<0.05$, eta squared $=0.741$ (medium effect)) and hyperactivity and concentration difficulties $(M=2.8, S D=2.4, p<0.05$, eta squared 1.15 (large effect)). There was also a significant decrease in impact scores $(M=1.636, S D=1.8, P<0.05$, eta squared $=0.909$ (large effect)).

There were no significant differences in the parent $(n=12)$ and self-reported SDQ $(n=12)$.

Table 4: SDQ pre and post Teacher 11-17 years $(n=33)$

\begin{tabular}{|c|c|c|c|c|c|c|c|c|c|}
\hline \multicolumn{10}{|l|}{ Paired Samples Test } \\
\hline \multirow{3}{*}{$\begin{array}{l}\text { SDQ Teacher 11-17 } \\
\text { years old }\end{array}$} & \multicolumn{5}{|c|}{ Paired Differences } & \multirow[t]{3}{*}{$\mathrm{t}$} & \multirow[t]{3}{*}{ df } & \multirow{3}{*}{$\begin{array}{l}\text { Sig. (2- } \\
\text { tailed) }\end{array}$} & \\
\hline & \multirow[t]{2}{*}{ Mean } & \multirow[t]{2}{*}{$\begin{array}{l}\text { Std. } \\
\text { Deviation }\end{array}$} & \multirow[t]{2}{*}{$\begin{array}{l}\text { Std. } \\
\text { Error } \\
\text { Mean }\end{array}$} & \multicolumn{2}{|c|}{$\begin{array}{l}95 \% \\
\text { Confidence } \\
\text { Interval of the } \\
\text { Difference }\end{array}$} & & & & \\
\hline & & & & Lower & Upper & & & & $\begin{array}{l}\text { Eta } \\
\text { squared } \\
\text { statistic } \\
\text { (Cohen) }\end{array}$ \\
\hline Total Difficulties & 6.242 & 6.165 & 1.073 & 4.057 & 8.428 & 5.817 & 32 & 0.000002 & $\begin{array}{l}1.013 \\
\text { (large } \\
\text { effect) }\end{array}$ \\
\hline Emotional Distress & 0.970 & 2.365 & 0.412 & 0.131 & 1.808 & 2.355 & 32 & 0.025 & $\begin{array}{l}0.450 \\
\text { (small } \\
\text { effect) }\end{array}$ \\
\hline $\begin{array}{l}\text { Behavioural/Conduct } \\
\text { Difficulties }\end{array}$ & 1.758 & 2.372 & 0.413 & 0.916 & 2.599 & 4.256 & 32 & 0.0002 & $\begin{array}{l}0.741 \\
\text { (medium } \\
\text { effect) }\end{array}$ \\
\hline $\begin{array}{l}\text { Hyperactivity and } \\
\text { Concentration } \\
\text { Difficulties }\end{array}$ & 2.758 & 2.398 & 0.417 & 1.907 & 3.608 & 6.605 & 32 & 0.0000002 & $\begin{array}{l}1.15 \\
\text { (large } \\
\text { effect) }\end{array}$ \\
\hline $\begin{array}{l}\text { Difficulties getting } \\
\text { along with others } \\
\text { (Peers) }\end{array}$ & 0.758 & 1.985 & 0.346 & 0.054 & 1.461 & 2.193 & 32 & 0.036 & $\begin{array}{l}0.382 \\
\text { (small } \\
\text { effect) }\end{array}$ \\
\hline $\begin{array}{l}\text { Kind and helpful } \\
\text { behaviour } \\
\text { (Prosocial) }\end{array}$ & -0.697 & 1.630 & 0.284 & -1.275 & -0.119 & -2.457 & 32 & 0.200 & $\begin{array}{l}0.428 \\
\text { (small } \\
\text { effect) }\end{array}$ \\
\hline IMPACT & 1.636 & 1.800 & 0.313 & 0.998 & 2.274 & 5.223 & 32 & 0.00001 & $\begin{array}{l}0.909 \\
\text { (large } \\
\text { effect) }\end{array}$ \\
\hline
\end{tabular}

\section{Discussion}


Lloyd Kolbe noted, "Our world and our nation have changed; so too have our schools.

Today, more than ever, school health programs could become one of the most efficient means available to improve the health of our children and their educational achievement."(3)

The movement toward health equity, especially for children, forces institutions and communities to consider the intertwined relationship between health and education $(3,33)$. High rates of chronic absence and suspensions from school, and low levels of literacy, are often rooted in health issues(3).

The cohort of students at YGS represent those on the more serious end of the externalising behaviours spectrum. Many of the students had a pre-existing DSM 5 diagnosis including ADHD (39.2\%), CD (12.7\%) and ODD (21.5\%). Child protection services (DCJ) were involved in $43 \%$ of cases in the past and $32.9 \%$ had an open case. Despite these risk factors only about a third of students were being seen by paediatric or mental health services and of these students about $20-30 \%$ were not engaged with the named services. This points to difficulty accessing existing services. By partnering with the school, high attendance rates at the medical assessment were achieved. The failure to attend (FTA) rate was $7.6 \%$ and the cancellation rate was $8.9 \%$. The reasons for FTA were varied but the reasons for cancelations were of interest. In some situations the clinic was cancelled because the clinician was unavailable or because the parent was unable to take time off work. In about a third of cases though cancellations were because of the child's behaviour. For example, the child was being oppositional, had not come home that night, had absconded from the home or was having a behavioural outburst. As such, it became apparent that these children were doubly disadvantaged. Not only did they require support with their behaviour, but it was that very behaviour that prevented them from accessing traditional health services. School based health facilities offer opportunities to address the shortcomings of health delivery systems by providing a place of familiarity and convenience(4).

The students who attended NS were provided an opportunity to have a thorough medical review including a psychosocial assessment and a medical examination. Where possible they also received dental, vision and hearing screening. A small proportion received a new DSM 5 diagnosis with ASD diagnosed in 2 children. This had a significant impact in that it led to a more complete understanding of the child's behaviour and allowed funding and therapy to be accessed. Other notable concerns that were identified included recognition of learning difficulties (12.7\%), medical diagnoses (10.1\%), emotional concerns (16.5\%), domestic violence (12.7\%), OOHC (7.6\%) and a trauma background (27.8\%).

The multidisciplinary approach meant that a more complete understanding of the families was gained. This included the impact of experiencing the death of a close relative or friend, parental separation and substance use. Health issues pertinent to young people were also explored including the identification of obesity, sexual health concerns and sleep difficulties. This reflects that children with externalising behaviour also have other health issues that may go unrecognised.

The multidisciplinary team formulated a holistic understanding of the child and family after the assessment. Based on this understanding, recommendations were made based on health, mental health, educational and social wellbeing needs. The model of care meant that various forms of counselling and therapy could be accessed at the school. This included ongoing speech therapy, occupational therapy, art therapy as well as trauma-informed behavioural management which is practised by the teaching staff.

The SDQ was used to assess changes in behaviour. The teacher SDQ showed a statistically significant decrease in the total difficulties scores $(n=33, M=6.2, S D=6.165, p<0.05$, eta squared $=1.013$ (large effect) $)$ and all subsets. There was also a significant decrease in impact scores $(M=1.636, S D=1.8, P<0.05$, eta squared $=0.909$ (large effect)).

Page $12 / 16$ 
These results concur with the Gonski report and are likely to be a reflection of the partnership between health and education, whereby health provided a more complete understanding of the child framed through a trauma lens that informed the ongoing strategies and teaching approaches used by the education team and therapists. This was promising as it meant that students were more likely to be accessing the education curriculum which has positive effects with regards to school completion and tertiary study(21).

There were no significant differences in the parent $(n=12)$ and self-reported $(n=12)$ SDQs. This differs to the Gonski report where parents reported a decrease in conduct problems. This may have been due to a small sample size. Other research shows that SDQ self-reports often lack significant differences due to issues with self-concept that are often experienced by adolescents with emotional and behavioural disabilities(34).

Achieving health equity and education equity go hand in hand. Collaboration between these two sectors is mutually beneficial and demands sustainable and productive partnerships $(33,35,36)$. This may be even more important for children with externalising behaviours. Evidence shows that a critical feature of interventions for older children and adolescents with $C D$ is a system for ensuring that mental health, medical, child welfare, and educational services are available. Additionally, a system for providing a comprehensive assessment to determine the specific needs of the young person and strong case-management to ensure that services are provided in an integrated and coherent manner have also been critical to $\operatorname{success}(9,10)$. The Gonski report identified enablers (interdisciplinary approach, flexibility, cultural responsiveness, individualised planning) and barriers (funding, professional resourcing, time, and case management) to the implementation of the NS program(21).

Given the personal and societal costs associated with externalising behaviours and its negative effects across the lifespan, advocacy for targeted programmes and prevention become paramount. Policy-makers and health-care commissioners are key to adopting a long-term perspective because the financial resources and commitment needed might not lead to reduced public spending until decades later(8). In the USA significant advocacy and federal attention has led to school-based mental health services becoming more widely available, with the majority (70-80\%) of mental health services for youth provided in schools(4).

The integrative and holistic model between health and education at NS offered mechanisms to reduce barriers to care for children experiencing externalising behaviours. The school provided a convenient place for children and caregivers to meet with health staff and the high attendance rates were suggestive of the acceptability of this model. Further qualitative research is needed to understand the model from the perspective of students, parents/caregivers, staff and the community.

\section{Conclusions}

Children and families experiencing problematic externalising behaviour at YGS often have unmet health and wellbeing needs. The multidisciplinary model between health and education offered mechanisms to reduce barriers to care. Teacher SDQ results are suggestive of improved behaviour. High attendance rates at the school-based clinic suggest initial acceptance of the model with further qualitative study into this area required.

\section{Declarations}

\section{Ethics approval and consent to participate}

Ethics number: 2020/ETH00532 
Full ethics applications were received from the Sydney Local Health District Human Research Ethics Committee (SLHD HREC), NSW State Education Research Applications Process (SERAP) and Aboriginal Health and Medical Research Council (AH\&MRC).

Consent to participate was waivered by the SLHD HREC.

\section{Availability of data and materials}

All relevant data is included in the manuscript. The datasets used and/or analysed during the current study are available from the corresponding author on reasonable request.

\section{$\underline{\text { Competing interests }}$}

The authors have no competing interests to declare.

\section{Funding}

This evaluation was done as part of usual clinical duties at Croydon Community Health Centre. There were no other funding bodies involved in this study.

\section{Authors' contributions}

JE and SR designed the study. SR analyzed and interpreted all the data. AM supported SR with data analysis. SR was a major contributor in writing the manuscript. JE, AM, JSM and HML contributed to editing. All authors read and approved the final manuscript.

\section{Acknowledgements}

The authors would like to acknowledge Patrick Faucher, Principal of Yudi Gunyi School, and the Wouwanguul Kanja Committee for their support of this initiative and its evaluation.

\section{Patient and Public Involvement}

This was a retrospective evaluation. As such patients were not involved in its design.

A community steering committee was formed to oversee the initiative and its evaluation. The committee is called 'Wouwanguul Kanja' and consists of members from the health sector, education sector and local Aboriginal community.

\section{References}

1. WHO. Preamble to the Constitution of the World Health Organization as adopted by the International Health Conference, New York, 19-22 June, 1946; signed on 22 July 1946 by the representatives of 61 States (Official Records of the World Health Organization, no. 2, p. 100) and entered into force on 7 April 1948. 1948.

2. UN. United Nations convention on the rights of children. 1989.

3. Richardson JW. Building bridges between school-based health clinics and schools. The Journal of School Health. 2007;77(7):337-43.

4. Bruns EJ, Duong MT, Lyon AR, Pullmann MD, Cook CR, Cheney D, et al. Fostering SMART partnerships to develop an effective continuum of behavioral health services and supports in schools. American Journal of 
Orthopsychiatry. 2016;86(2):156.2016;86(2):156.

5. Kolbe LJ, Allensworth DD, Potts-Datema W, White DR. What have we learned from collaborative partnerships to concomitantly improve both education and health? Journal of School Health 2015;85(11):766-74.

6. WHO. The ICD-10 classification of mental and behavioural disorders: clinical descriptions and diagnostic guidelines: World Health Organization; 1992.

7. First MB. DSM-5 handbook of differential diagnosis. American Psychiatric Pub; 2013 Nov 19.

8. Fairchild G, Hawes DJ, Frick PJ, Copeland WE, Odgers CL, Franke B, Freitag CM, De Brito SA. Conduct disorder. Nature Reviews Disease Primers. 2019 Jun 27;5(1):1-25.

9. Frick PJ. Developmental pathways to conduct disorder. Child and Adolescent Psychiatric Clinics. 2006 Apr 1;15(2):311-31.

10. Frick PJ. Developmental pathways to conduct disorder: Implications for future directions in research, assessment, and treatment. Journal of clinical child \& adolescent psychology. 2012 May 1;41(3):378-89.

11. Pilling S, Gould N, Whittington C, Taylor C, Scott S. Recognition, intervention, and management of antisocial behaviour and conduct disorders in children and young people: summary of NICE-SCIE guidance. Bmj. 2013 Mar $27 ; 346$.

12. Jaffee SR, Caspi A, Moffitt TE, Dodge KA, Rutter M, Taylor A, Tully LA. Naturex nurture: Genetic vulnerabilities interact with physical maltreatment to promote conduct problems. Development and psychopathology. 2005;17(1):67.

13. Gelhorn H, Stallings M, Young S, Corley R, Rhee $\mathrm{SH}$, Christian $\mathrm{H}$, et al. Common and specific genetic influences on aggressive and nonaggressive conduct disorder domains. 2006;45(5):570-7.

14. Wesseldijk LW, Bartels M, Vink JM, van Beijsterveldt CE, Ligthart L, Boomsma DI, Middeldorp CM. Genetic and environmental influences on conduct and antisocial personality problems in childhood, adolescence, and adulthood. European child \& adolescent psychiatry. 2018 Sep;27(9):1123-32.

15. Jacobson KC, Prescott CA, Kendler KS. Sex differences in the genetic and environmental influences on the development of antisocial behavior. Development and Psychopathology. 2002 Jun;14(2):395-416.

16. Beaudry G, Yu R, Långström N, Fazel S. An updated systematic review and meta-regression analysis: mental disorders among adolescents in juvenile detention and correctional facilities. Journal of the American Academy of Child \& Adolescent Psychiatry. 2021 Jan 1;60(1):46-60.

17. Bickel R, Campbell A. Mental health of adolescents in custody: the use of the 'Adolescent Psychopathology Scale'in a Tasmanian context. Australian \& New Zealand Journal of Psychiatry. 2002 Oct;36(5):603-9.

18. Dixon A, Howie P, Starling J. Psychopathology in female juvenile offenders. Journal of child psychology and psychiatry. 2004 Sep;45(6):1150-8.

19. Kenny DT, Lennings CJ. Cultural group differences in social disadvantage, offence characteristics, and experience of childhood trauma and psychopathology in incarcerated juvenile offenders in NSW, Australia: Implications for service delivery. Psychiatry, Psychology and Law. 2007 Nov 1;14(2):294-305.

20. Dingwall KM, Cairney S. Psychological and cognitive assessment of Indigenous Australians. The Australian and New Zealand Journal of Psychiatry. 2010;44(1):20-30.

21. GONSKI. Yudi Gunyi School Ngaramadhi Space Wraparound Program Research Project. Sydney, Australia: Gonski Institute for Education; 2020.

22. Goodman R. Psychometric properties of the strengths and difficulties questionnaire. Journal of the American Academy of Child \& Adolescent Psychiatry. 2001 Nov 1;40(11):1337-45. 
23. Harris PA, Taylor R, Thielke R, Payne J, Gonzalez N, Conde JG. Research electronic data capture (REDCap)-a metadata-driven methodology and workflow process for providing translational research informatics support. Journal of biomedical informatics. 2009 Apr 1;42(2):377-81.

24. Muris $P$, Meesters $C$, van den Berg F. The strengths and difficulties questionnaire (SDQ). European child \& adolescent psychiatry. 2003 Feb;12(1):1-8.

25. Goodman R, Meltzer H, Bailey V. The Strengths and Difficulties Questionnaire: a pilot study on the validity of the self-report version. European child \& adolescent psychiatry. 1998 Oct;7(3):125-30.

26. Goodman R. The Strengths and Difficulties Questionnaire: a research note. Journal of child psychology and psychiatry. 1997 Jul;38(5):581-6.

27. Goodman R, Ford T, Simmons H, Gatward R, Meltzer H. Using the Strengths and Difficulties Questionnaire (SDQ) to screen for child psychiatric disorders in a community sample. The British journal of psychiatry. 2000 Dec;177(6):534-9.

28. Blair EM, Zubrick SR, Cox AH. The Western Australian Aboriginal Child Health Survey: findings to date on adolescents. The Medical journal of Australia. 2005;183(8):433-5.

29. Dray J, Bowman J, Freund M, Campbell E, Hodder RK, Lecathelinais C, Wiggers J. Mental health problems in a regional population of Australian adolescents: association with socio-demographic characteristics. Child and adolescent psychiatry and mental health. 2016 Dec;10(1):1-1.

30. Priest N, Baxter J, Hayes L. Social and emotional outcomes of Australian children from Indigenous and culturally and linguistically diverse backgrounds. Australian and New Zealand Journal of Public Health. 2012 Apr;36(2):183-90.

31. Williamson A, Redman S, Dadds M, Daniels J, D'Este C, Raphael B, Eades S, Skinner T. Acceptability of an emotional and behavioural screening tool for children in Aboriginal Community Controlled Health Services in urban NSW. Australian \& New Zealand Journal of Psychiatry. 2010 Oct;44(10):894-900.

32. Statistics ABo. Estimates of Aboriginal and Torres Strait Islander Australians 2016 [cited 202120 April]. Available from: https://www.abs.gov.au/statistics/people/aboriginal-and-torres-strait-islander-peoples/estimatesaboriginal-and-torres-strait-islander-australians/jun-2016.

33. Blank MJ. Building sustainable health and education partnerships: Stories from local communities. Journal of school health. 2015 Nov;85(11):810-6.

34. Gage NA, Lierheimer K. Exploring self-concept for students with emotional and/or behavioral disorders as they transition from elementary to middle school and high school. Education Research International. 2012 Jan 1;2012.

35. Svirydzenka N, Aitken J, Dogra N. Research and partnerships with schools. Social psychiatry and psychiatric epidemiology. 2016 Aug;51(8):1203-9.

36. Castillo EG, ljadi-Maghsoodi R, Shadravan S, Moore E, Mensah MO, Docherty M, Nunez MG, Barcelo N, Goodsmith $\mathrm{N}$, Halpin LE, Morton I. Community interventions to promote mental health and social equity. Current psychiatry reports. 2019 May;21(5):1-4.y. 2019;21(5):1-14. 